УДК 595.132

\title{
НЕМАТОЛОГИЧЕСКИЕ ИССЛЕДОВАНИЯ НА СКЛОНАХ ВУЛКАНА ТОЛБАЧИК (КаМчаТКа)
}

\author{
Волкова Т. В. \\ Федеральный научный иентр биоразнообразия наземной биоты Восточной Азии ДВО РАН, \\ 2. Владивосток \\ E-mail: volkova@biosoil.ru
}

\begin{abstract}
После извержения 2013 г. впервые исследована фауна почвенных нематод 5 участков на территории вулкана Толбачик. Выявлены представители 25 родов нематод. Изучены состав и структура нематодных сообществ. По типу питания преобладают фитофаги.
\end{abstract}

\section{Ключевые слова: почвенные нематоды, индексы разнообразия, численность, структура сообществ нематод, вулкан Толбачик, Камчатский край.}

DOI: $10.34078 / 1814-0998-2020-3-60-65$

Нематоды представляют собой обширную группу беспозвоночных животных, распространенных во всех климатических зонах земного шара и играющих немаловажную роль в наземных биоценозах. В настоящее время всё большую поддержку находит предположение о возможности экологической оценки почвенных условий на основе сообществ нематод. Нематоды являются широко распространенной группой беспозвоночных, которые обитают практически в любом биотопе и могут составлять от 80 до $90 \%$ численности многоклеточных организмов в почве (Bongers, 1990; Neher, 1999).

В настоящее время на Дальнем Востоке России известно около 550 видов почвообитающих нематод, из которых более 160 видов паразитируют на растениях (Волкова, Казаченко, 2010). Во время естественного процесса сукцессии почвенных и растительных биоценозов происходят изменения в сообществах нематод, что облегчает оценку «качества» среды и позволяет использовать нематод как индикатор при нарушении и восстановлении экосистем. Данная тематика является актуальной не только для Дальнего Востока, но и для всей мировой нематологии (Bongers, 1990, 1999; Волкова и др., 2010). Свободноживущие нематоды имеют ряд существенных преимуществ для использования их как биоиндикатора в сравнении с другими группами организмов. Они практически сами не мигрируют, имеют очень короткий цикл развития при крайне высокой чувствительности к среде обитания (т. е. при изменении условий среды структура не-

(C) Волкова Т. В., 2020 матодного сообщества очень быстро изменяется), повсеместно распространены (это позволяет интерпретировать и обобщать результаты, полученные в разных регионах планеты), относительно легко могут быть собраны. В этой работе индексы разнообразия можно будет применить при дальнейшем изучении нематод как индикатора при восстановлении данной экосистемы. Цель работы - изучение таксономического разнообразия почвенных нематод и структуры их экологофаунистических сообществ в экосистеме вулкана после извержения 2013 г. На данной территории нематологические исследования практически не проводились, поэтому наши исследования носят приоритетный характер.

\section{МАТЕРИАЛ И МЕТОДЫ}

Материалом для исследований послужили полевые сборы почвенных нематод в 2014 г., через полгода после извержения на лавовых потоках влк. Толбачик в Камчатском крае, где отобрано 76 почвенных образцов от нижней части южного склона влк. Плоский Толбачик, по левой стороне от свежего лавового потока на пяти площадках размерами $5 \times 5$ м, на расстоянии 500 м друг от друга из ризосферы вейника полуторацветкового Calamagrostis sesquiflora (Trin.) Trin. Ha пробной площадке 1 напочвенный покров сомкнутый и практически весь покрыт мхом, преобладает кочкарный тип луговой растительности. Вейник полуторацветковый встречался пятачками, образующими дерновины диаметром до 30 см. Пробная площадка 2 имеет выровненный лавовый поток и сходные условия положения микрорельефа, как в описании площадки 1. Рас- 
тительность представлена лугово-тундровым сообществом. Вейник полуторацветковый образует кочки с плотной компактной дерновиной высотой 10-12 см диаметром 15 см. Пробная площадка 3 имеет небольшой северо-восточный наклон в 2-5․ Большая часть растительности приурочена к временным водотокам и располагается по его склонам, не встречаясь на открытом пространстве тефры. Пробная площадка 4 с достаточно пологим выровненным лавовым потоком северо-западной экспозиции крутизной $3^{\circ}$. Растительный покров достаточно хорошо сформирован лишь вдоль водотоков, а на открытых участках разреженный. На пробной площадке 5 вершина лавового потока достаточно выровненная, синузии вейника полуторацветкового встречаются группировками, образующими дерновины диаметром до 15 см. Площадки были расположены на высоте от 1546 до 1685 м н. у. м., на долготе от 5546'295" до 5546'072", на широте от $160^{\circ} 21^{\prime} 908^{\prime \prime}$ до 160²0'065". Пробы отбирали на глубине 10-15 см, в ризосфере корней растений из расчета 100 г почвы на 1 пробу. С каждой площадки было отобрано от 12 до 16 проб.

Нематоды из почвы выделяли центрифужнофлотационным методом (Jenkins, 1964), фиксировали в 4\%-ном формальдегиде. Просветление и приготовление постоянных глицериновых препаратов нематод (с окантовкой парафином) проводили по методу Сейнхорста (Seinhorst, 1959). Эколого-трофическое группирование нематод осуществляли по классификации (Yeates et al., 1993). Для характеристики биоразнообразия были применены индекс трофического разнообразия (Т), индекс Зрелости (MI), отражающий стабильность нематодного сообщества по шкале Бонгерса с-р от 1 до 5, индекс разнообразия Шеннона $\left(\mathrm{H}^{\prime}\right)$, считающийся одним из основных по надежности и удобству для практического применения (Песенко, 1982; Мэгарран, 1992; Wasilewska, 1997). Определение видовой и родовой принадлежности нематод осуществляли по имеющимся определителям и каталогам (Кирьянова, Кралль, 1969; Siddiqi, 2000; Ерошенко, Волкова, 2005).

Встречаемость представителей различных таксонов в эколого-фаунистических комплексах показана в процентом отношении количества проб, в которых они обнаружены, к общему количеству проанализированных проб в конкретном комплексе. Доля участия каждого таксона в составе фауны показана как отношение (в \%) количества особей данного таксона к общему количеству нематод: эудоминанты - 10\% и более от всех обнаруженных нематод, доминанты 5-10\%, субдоминанты - 2-5\% и субрецеденты менее 1\% (Соловьева, 1986).
Учет почвенных нематод проводили с помощью микроскопа МБС-10 для выборки червей из фиксатора на предметное стекло и высокоразрешающего светового микроскопа БИОЛАР с объективами $5^{*}-40^{*}$, на котором определяли родовую принадлежность нематод и выполняли их количественный подсчет. Мелкие размеры особей затрудняют их количественный учет. Численность нематод устанавливается путем прямого счета в небольшом объеме фиксированной пробы с последующим перерасчетом на весь изучаемый образец. На основе полученных данных затем определяли плотность заселения почвы нематодами на 1 м² слоя толщиной до 20 см (Там же).

Масса нематод была рассчитана по формуле, предложенной в 1956 г. I. Andrassy (Цит. по: Coловьева, 1986):

$$
\mathrm{G}=\left(a^{2} \cdot b\right) /(16 \cdot 1000),
$$

где $a^{2}-$ квадрат наибольшей ширины нематоды, $b$ - длина тела.

Индекс Зрелости (MI) нематодного сообщества рассчитывали в целях оценки состояния почвенной экосистемы при дальнейшем мониторинге. Определяется он на основе состава и численности таксонов нематод с различными экологическими особенностями:

$$
\mathrm{MI}=\sum v(i) f(i),
$$

где $v(i)$ - индекс таксона, $f(i)$ - частота встречаемости этого таксона в образце.

Зарубежными нематологами (Bongers, 1990, 1999; Wasilewska, 1997) семейства нематод классифицированы на 5 групп по так называемой с-р шкале, где значение 1 имеют нематоды, обладающие коротким жизненным циклом, высокой репродуктивной скоростью, способностью к колониальному заселению, хорошей устойчивостью к нарушению экологической обстановки - «колонизаторы». Индекс c-p5 имеют нематоды с длинным жизненным циклом, ограниченной способностью селиться колониями, небольшим количеством поколений, чувствительностью к экологическим нарушениям - «постояльцы». Соответственно, нематоды с индексами c-p2, c-p3, c-p4 относятся к постоянно обитающим. Индекс Зрелости МI является средним значением для индексов с-р в конкретном образце и может колебаться от 4 на богатых питательными веществами почвах до 1 на бедных почвах.

\section{РЕЗУЛЬТАТЫ И ОБСУЖДЕНИЕ}

Толбачик - не одинокая гора, а целый вулканический массив. Его главные вершины - Острый Толбачик и Плоский Толбачик (рис. 1.) Вокруг них громоздятся десятки гребней и конусов поменьше. 


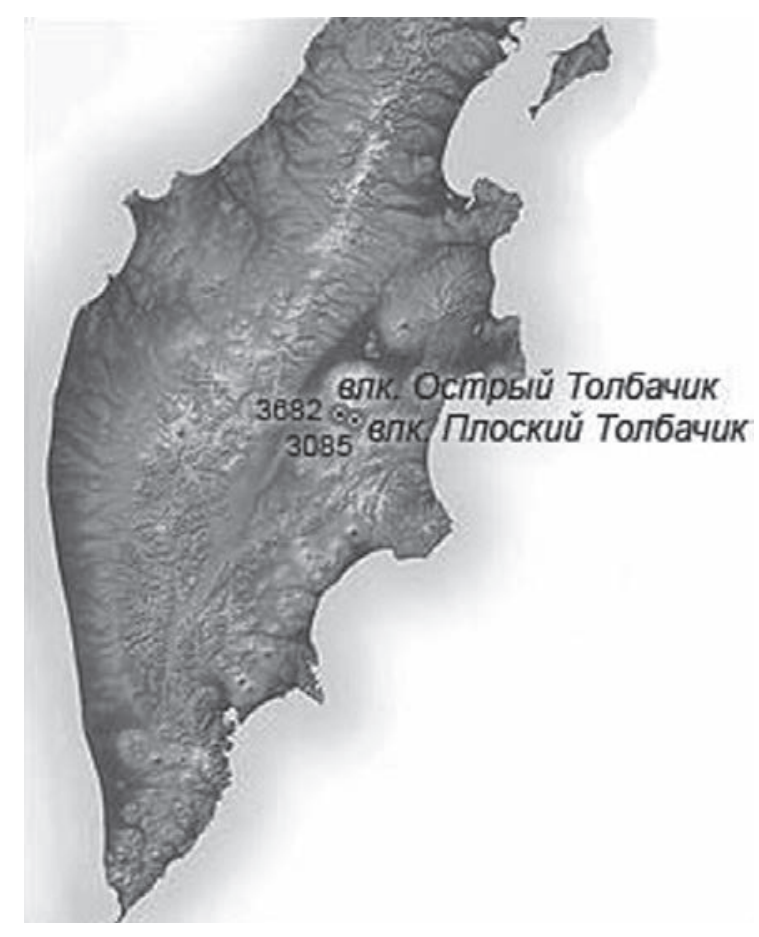

Puc. 1. Местоположение Толбачинской группы вулканов

Fig. 1. Location of the Tolbachik volcano group

Плоский Толбачик - вулкан действующий, а значит, заслуживает самого серьезного отношения. Острый Толбачик, напротив, никакой опасности не представляет, он потухший. Подъем на Плоский Толбачик чаще всего производится с южной стороны - от сейсмостанции, расположенной немного выше слияния Правого и Левого Толудов. Путь пересекают старые лавовые поля и потоки. До 1975 г. нижняя часть этого южного склона была покрыта островками кустарников и травой.

К настоящему времени для фауны нематод влк. Толбачик определены представители 25 ро-

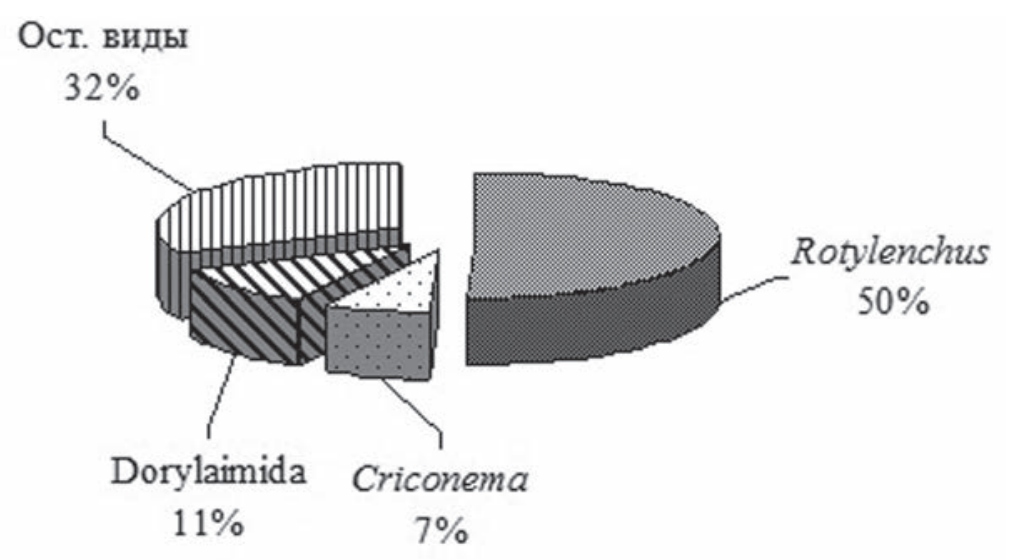

Pис. 2. Процентное соотношение доминирующих родов нематод в естественных ценозах склона влк. Толбачик

Fig. 2. Percentage ratio of predominant nematode genera in natural cenoses of the Tolbachik Volcano slope дов из различных трофических групп, где доминируют нематоды родов Rotylenchus, Criconema и отряда Dorylaimida. Доминирующая группа составляет $68 \%$ от общей численности нематод в данном ценозе (рис. 2).

Эколого-таксономический анализ видового состава нематод свидетельствует о том, что в нем преобладают фитофаги и нематоды, связанные с растениями. Нематоды этой группы составляют 10 родов (70\%), где доминантами по численности являются представители рода Rotylenchus. Из 10 представителей бактериофагов (17.3\%) в пробах постоянно присутствуют плектиды и цефалобиды, но по численности доминируют Aphanolaimus и Anaplectus. Всеядные нематоды-полифаги (2 таксона) представлены родами Dorylaimus и Eudorylaimus. Их встречаемость составила $10.6 \%$. Самый незначительный процент фауны составляют 2 рода хищных нематод $(1.8 \%)$ и 1 род микофагов $(0.2 \%)$ (табл. 1$)$.

В результате изучения видового состава на пробной площадке 1 в ризосфере вейника полуторацветкового выявлено 15 родов нематод. По эколого-трофическому группированию не было отмечено микофагов. Индексы Шеннона и трофического разнообразия показали наименьшие значения, так как в данном биотопе доминирует группа фитофагов (более $94 \%$ от общей численности нематод). Индекс зрелости нематодного сообщества - наибольший (табл. 2) также за счет большого количества фитофагов, имеющих значение с-р3-5 по шкале Бонгерса. Доминирование фитопаразитических форм нематод связано с увеличением корневой системы растений.

На пробной площадке 2 выявлено 14 родов. По эколого-трофическому группированию нематод преобладали представители семейства Criconematidae из группы фитофагов (более 60\%). Микофаги и хищники отмечены в единичных количествах. Остальные группы нематод были почти равномерно распределены в сообществе.

Пробная площадка 3 включала 13 родов нематод. Здесь отмечен самый высокий показатель трофического разнообразия $(\mathrm{T}=4.17)$ за счет равномерного распределения групп нематод и один из наибольших индексов зрелости сообщества.

Пробная площадка 4 характеризовалась наименьшим количеством родов (7) и плотностью нематод. Низкие показатели индекса Шеннона и трофического разнообразия - за счет доминирования фитофагов (более 65\%).

На пробной площадке 5 выявлено 14 родов нематод и относи- 
Таблица 1. Встречаемость и доминирование почвенных нематод на склоне влк. Толбачик Table 1. Occurrence and dominance of soil nematodes on the Tolbachik Volcano slope

\begin{tabular}{|c|c|c|c|c|c|c|c|c|c|c|c|}
\hline \multirow[b]{3}{*}{ Род нематод } & \multirow[b]{3}{*}{ Гр.* } & \multicolumn{10}{|c|}{ № площадки } \\
\hline & & \multicolumn{2}{|c|}{1} & \multicolumn{2}{|c|}{2} & \multicolumn{2}{|c|}{3} & \multicolumn{2}{|c|}{4} & \multicolumn{2}{|c|}{5} \\
\hline & & $\begin{array}{c}\text { Встре- } \\
\text { чаемо- } \\
\text { сть }\end{array}$ & $\begin{array}{c}\text { Доми- } \\
\text { нирова- } \\
\text { ние }\end{array}$ & $\begin{array}{c}\text { Встре- } \\
\text { чаемо- } \\
\text { сть }\end{array}$ & $\begin{array}{c}\text { Доми- } \\
\text { нирова- } \\
\text { ние }\end{array}$ & $\begin{array}{c}\text { Встре- } \\
\text { чаемо- } \\
\text { сть }\end{array}$ & $\begin{array}{c}\text { Доми- } \\
\text { нирова- } \\
\text { ние }\end{array}$ & $\begin{array}{c}\text { Встре- } \\
\text { чаемо- } \\
\text { сть }\end{array}$ & $\begin{array}{c}\text { Доми- } \\
\text { нирова- } \\
\text { ние }\end{array}$ & $\begin{array}{l}\text { Встре- } \\
\text { чаемо- } \\
\text { сть }\end{array}$ & $\begin{array}{c}\text { Доми- } \\
\text { нирова- } \\
\text { ние }\end{array}$ \\
\hline Helicotylenchus & Пр. & 31.2 & 0.6 & 0 & 0 & 0 & 0 & 0 & 0 & 12.5 & 0.5 \\
\hline Rotylenchus & Пр. & 100.0 & 89.4 & 12.5 & 1.6 & 12.5 & 4.7 & 0 & 0 & 18.75 & 2.4 \\
\hline Nagelus & Пр. & 25.0 & 0.6 & 0 & 0 & 6.25 & 1.2 & 0 & 0 & 0 & 0 \\
\hline Geocenamus & Пр. & 0 & 0 & 6.25 & 1.6 & 12.5 & 4.7 & 0 & 0 & 0 & 0 \\
\hline Criconema & Пр. & 0 & 0 & 6.25 & 1.6 & 0 & 0 & 33.3 & 66.0 & 56.25 & 12.4 \\
\hline Hemicycliophora & Пр. & 25.0 & 3.7 & 25.0 & 42.6 & 0 & 0 & 0 & 0 & 0 & 0 \\
\hline Aglenchus & Acp & 12.5 & 0.4 & 0 & 0 & 0 & 0 & 0 & 0 & 0 & 0 \\
\hline Lelenchus & Acp & 6.25 & 0.2 & 0 & 0 & 0 & 0 & 0 & 0 & 0 & 0 \\
\hline Filenchus & Acp & 25.0 & 1.2 & 18.75 & 8.2 & 0 & 0 & 0 & 0 & 0 & 0 \\
\hline Cephalenchus & Acp & 37.5 & 1.0 & 12.5 & 4.9 & 68.75 & 34.5 & 33.3 & 9.0 & 6.25 & 0.5 \\
\hline Aphelenchus & $\mathrm{M}$ & 0 & 0 & 12.75 & 3.3 & 0 & 0 & 0 & 0 & 0 & 0 \\
\hline Monhystera & Б & 0 & 0 & 0 & 0 & 0 & 0 & 0 & 0 & 50.0 & 10.5 \\
\hline Aphanolaimus & Б & 0 & 0 & 0 & 0 & 0 & 0 & 0 & 0 & 6.25 & 18.1 \\
\hline Plectus & Б & 12.5 & 0.2 & 50.0 & 4.9 & 25.0 & 2.4 & 50.0 & 7.1 & $75 . .0$ & 3.3 \\
\hline Anaplectus & Б & 12.5 & 0.2 & 0 & 0 & 0 & 0 & 0 & 0 & 50.0 & 16.7 \\
\hline Cephalobus & Б & 12.5 & 1.2 & 50.0 & 6.5 & 12.5 & 2.4 & 43.75 & 3.6 & 100.0 & 3.3 \\
\hline Eucephalobus & Б & 0 & 0 & 0 & 0 & 12.5 & 2.4 & 0 & 0 & 25.0 & 1.4 \\
\hline Prismatolaimus & Б & 6.25 & 0.2 & 12.75 & 4.9 & 18.75 & 3.6 & 0 & 0 & 0 & 0 \\
\hline Alaimus & Б & 0 & 0 & 0 & 0 & 6.25 & 1.2 & 0 & 0 & 0 & 0 \\
\hline Wilsonema & Б & 0 & 0 & 0 & 0 & 6.25 & 2.4 & 0 & 0 & 0 & 0 \\
\hline Bastiania & Б & 0 & 0 & 6.25 & 3.3 & 0 & 0 & 6.25 & 1.8 & 12.5 & 3.3 \\
\hline Dorylaimus & $\Pi$ & 18.75 & 0.2 & 62.50 & 11.5 & 43.75 & 7.1 & 12.5 & 3.6 & 100.0 & 14.8 \\
\hline Eudorylaimus & $\Pi$ & 18.75 & 0.4 & 43.75 & 3.3 & 18.75 & 19.0 & 18.75 & 9.0 & 56.25 & 12.4 \\
\hline Mononchida & $\mathrm{X}$ & 0 & 0 & 0.06 & 1.6 & 18.75 & 14.3 & 0 & 0 & 0.06 & 0.5 \\
\hline Tripyla & $\mathrm{X}$ & 25.0 & 0.6 & 0 & 0 & 0 & 0 & 0 & 0 & 0 & 0 \\
\hline
\end{tabular}

*Группы нематод: Пр. - паразиты растений; Аср - нематоды, ассоциирующие с растениями; М - микофаги; Б бактериофаги; П - полифаги; $\mathrm{X}$ - хищники.

Таблииа 2. Характеристика сообществ почвенных нематод вулканических ценозов

Table 2. Characteristics of soil nematode communities in volcanic cenoses

\begin{tabular}{|c|c|c|c|c|c|}
\hline \multirow{2}{*}{$\begin{array}{l}\text { № пло- } \\
\text { щадки }\end{array}$} & \multicolumn{4}{|c|}{ Индексы разнообразия } & \multirow{2}{*}{$\begin{array}{c}\text { Кол-во } \\
\text { родов }\end{array}$} \\
\hline & $\mathrm{T}$ & $\mathrm{H}^{\prime}$ & MI & $\mathrm{N}$ & \\
\hline 1 & 1.13 & 0.563 & 2.96 & 2040 & 15 \\
\hline 2 & 3.5 & 2.046 & 2.80 & 244 & 14 \\
\hline 3 & 4.17 & 2.020 & 2.93 & 336 & 13 \\
\hline 4 & 2.10 & 1.204 & 2.91 & 224 & 7 \\
\hline 5 & 2.39 & 2.210 & 2.59 & 840 & 14 \\
\hline Общая & 2.256 & 1.925 & 2.87 & 3684 & 25 \\
\hline
\end{tabular}

тельно средняя плотность. Наибольшая встречаемость отмечена у группы бактериофагов, характеризующихся значением в основном от 1 до 2. Данная группа нематод может обитать в нарушенных ценозах. Относительно низкое значение индекса зрелости, отмеченное в про- бе 5, указывает на сукцессионную незрелость биотопа.

Всего в отобранных образцах выявлены 1842 нематоды, относящиеся к 25 родам и 17 семействам. Индекс трофического разнообразия варьирует от 1.13 до 4.17 (см. табл. 2). Почти во всех группах нематод имеется доминирование какойлибо трофической группы. Наименьший индекс трофического разнообразия имеет фауна нематод в пробе 1, так как в данном биотопе доминирует группа фитофагов (68\% от общей численности нематод). Плотность заселения нематодами почвы в обследованных биотопах различная: наиболее высокая - в пробе 1, самая низкая - в пробе 4. Наиболее высокое родовое систематическое разнообразие отмечено в почвенных пробах 1, 2, 3, 5 (13-15 родов), наиболее низкое - в пробе 4 (7 родов).

Индекс Шеннона $\left(\mathrm{H}^{\prime}\right)$ принимает значения от 0.6 до 1.2 в двух точках (участки 1 и 4) и от 2.6 до 3.0 - в 3 точках (участки 2, 3, 5). Визуально от- 
мечено, что на 4-м участке растительность почти отсутствует по сравнению с другими участками, в пробах наименьшее количество нематод. На участке 1 индекс Шеннона имеет низкое значение вследствие малого трофического разнообразия, нематодное сообщество на 70\% представлено одним видом Rotylenchus alpinus.

На основе измерений нематод были подсчитаны средние значения массы нематод для отрядов, а сумма этих значений составила их общую биомассу (табл. 3).

Таблиц̧а 3. Численность, биомасса и индекс зрелости сообществ почвенных нематод на склоне влк. Толбачик

Table 3. Abundance, biomass, and maturity index of soil nematode communities on the Tolbachik Volcano slope

\begin{tabular}{|l|c|c|c|c|c|}
\hline $\begin{array}{c}\text { № пло- } \\
\text { щадки }\end{array}$ & $\begin{array}{c}\text { Кол-во } \\
\text { проанали- } \\
\text { зированных } \\
\text { проб }\end{array}$ & $\begin{array}{c}\text { Кол-во } \\
\text { выден- } \\
\text { ныхе- } \\
\text { матод }\end{array}$ & $\begin{array}{c}\text { Кол-во } \\
\text { нематод } \\
\text { на 1 }{ }^{2}, \\
\text { тыс. } \\
\text { экз. }\end{array}$ & $\begin{array}{c}\text { Био- } \\
\text { масса } \\
\text { нема- } \\
\text { тод } \\
\text { на } \\
1 \mathrm{M}^{2}, \text { г }\end{array}$ & $\Sigma \mathrm{MI}$ \\
\hline 1 & 16 & 2040 & 170 & 0.0468 & 2.96 \\
\hline 2 & 16 & 244 & 20 & 0.0115 & 2.80 \\
\hline 3 & 16 & 336 & 28 & 0.0286 & 2.93 \\
\hline 4 & 12 & 224 & 25 & 0.0172 & 2.91 \\
\hline 5 & 16 & 840 & 70 & 0.0217 & 2.59 \\
\hline
\end{tabular}

\section{ЗАКЛЮЧЕНИЕ}

Результаты почвенных нематологических исследований показали, что качественный состав нематодофауны на склоне влк. Толбачик имеет значительное таксономическое разнообразие. Здесь отмечено 25 родов нематод из различных трофических групп, из которых доминирующими являются представители фитофагов из сем. Hoplolaimidae, предпочитающие песчаные почвы и широко распространенные в лесах Дальнего Востока. Эудоминантами из фитофагов во всех обследованных биотопах являлись нематоды сем. Criconematidae, с преобладанием видов из родов Criconema, и хищные нематоды отряда Dorylaimida. По структуре сообществ нематод можно делать предположения о сукцессионных изменениях. Большинство таксонов нематод, населяющих почву на склоне вулкана, имеют значение 2 и 3 , относятся к постоянным обитателям обследованных биотопов и отражают естественную ненарушенную среду обитания. Результаты проведенных исследований позволяют утверждать, что устойчивость естественных экосистем относительно быстро нивелирует последствия загрязнений, например, быстрым увеличением фитофагов. Необходимо дальнейшее проведение исследований.

\section{ЛИТЕРАТУРА}

Волкова Т. В., Казаченко И. П. Каталог фитонематод (Nematoda. Tylenchida) Дальнего Востока России. Владивосток : Дальнаука, 2010.121 с.

Волкова Т. В., Кльшевская С. В., Казаченко И. П. Фауна почвообитающих нематод в прибрежных ценозах бассейна Нижнего Амура // Вестник КРасГАУ. 2010. Вып. 7. С. 81-86.

Ерошенко А. С., Волкова Т. В. Нематоды растений Дальнего Востока России. Отряды Tylenchida и Aphelenchida. Владивосток : Дальнаука, 2005. 226 с.

Кирьянова Е. С., Кралль Э. Л. Паразитические нематоды и меры борьбы с ними. Ленинград : Наука, 1969. T. $1.447 \mathrm{c.}$

Мэгарран Э. Экологическое разнообразие и его измерение. Москва : Мир, 1992. 181 с.

Песенко Ю. А. Принципы и методы количественного анализа в фаунистических исследованиях. Москва : Наука, 1982. 281 с.

Соловьева Г. И. Экология почвенных нематод. Ленинград : Наука, 1986. 247 с.

Bongers T. The Maturity Index: an ecological measure of environmental disturbance based on nematode species composition // Oecologia. 1990. Vol. 83. P. 14-19.

Bongers T. The Maturity Index, the evolution of nematode life history traits, adaptive radiation and cpscaling // Plant and Soil. 1999. Vol. 212. P. 13-22.

Jenkins $W . R$. A rapid centrifugation-flotation technique for separating of nematodes from soil // Plant Disease Reporter. 1964. Vol. 48. P. 632.

Neher D. A. Soil community composition and ecosystem processes // Agroforestry Systems. 1999. Vol. 4. P. $159-185$.

Seinhorst J. W. A rapid method for the transfer of nematodes from fixative to anhydrous glycerin // Nematologica. 1959. Vol. 4, No. 1. P. 67-69.

Siddiqi M. R. Tylenchida. Parasites of plants and insects: $2^{\text {nd }}$ Edition. St. Albans, Commonwealth Agricultural Bureaux. 2000. 848 p.

Wasilewska L. Soil invertebrates as bioindicators, with special reference to soil-inhabiting nematodes // Russian Journal of Nematology. 1997. Vol. 5, No. 2. P. 113-126.

Yeates G. W., Bongers T., De Goede R. G. M., Freckman, D. W., Georgieva, S. S. Feeding habits in soil nematode families and genera - An outline for soil ecologists // Ibid. 1993. Vol. 25. P. 315-331. 


\title{
NEMATOLOGICAL RESEARCH ON THE SLOPES OF THE TOLBACHIK VOLCANO (Kamchatka)
}

\author{
T. V. Volkova \\ Federal Scientific Center for Biodiversity of Terrestrial Biota of East Asia, FEB RAS, Vladivostok \\ For the first time since the 2013 eruption,the fauna of soil nematodes from 5 sites on the territory of \\ the Tolbachik Volcano has been researched. Representatives of 25 genera of nematodes have been \\ identified. The composition and structure of nematode communities have been studied. According \\ to the type of nutrition, phytophages predominate.
}

Keywords: soil nematodes, diversity indices, population, structure of nematode communities, Tolbachik Volcano, Kamchatka Krai.

\section{REFERENCES}

Bongers, T., 1990. The Maturity Index: an Ecological Measure of Environmental Disturbance Based on Nematode Species Composition, Oecologia. 83, 14-19.

Bongers, T., 1999. The Maturity Index, the Evolution of Nematode Life History Traits, Adaptive Radiation and Cp-scaling, Plant and Soil. 212, 13-22.

Eroshenko, A. S., Volkova, T. V., 2005. Nematodes of Plants of the Far East of Russia, Orders Tylenchida and Aphelenchida. Vladivostok, Dal'nauka [In Russian].

Jenkins, W. R., 1964. A Rapid Centrifugation-Flotation Technique for Separating of Nematodes from Soil, Plant Disease Reporter, 48.

Kiryanova, E. S., Krall, E. L., 1969. Parasitic Nematodes and Control Measures. Leningrad, Science. 1 [In Russian].

Magarran, E., 1992. Ecological Diversity and Its Measurement. Moscow, Mir [In Russian].

Neher, D. A., 1999. Soil Community Composition and Ecosystem Processes, Agroforestry Systems. 4, 159-185.

Pesenko, Yu. A., 1982. Principles and Methods of Quantitative Analysis in Faunistic Studies. Moscow, Science [In Russian].
Seinhorst, J. W., 1959. A Rapid Method for the Transfer of Nematodes from Fixative to Anhydrous Glycerin, Nematologica. 4, 1, 67-69.

Siddiqi, M. R., 2000. Tylenchida, Parasites of Plants and Insects, $2^{\text {nd }}$ Edition, St. Albans, Commonwealth Agriccultural Bureaux.

Solovyova, G. I., 1986. Ecology of Soil Nematodes. Leningrad, Science [In Russian].

Volkova, T. V., Kazachenko, I. P., 2010. Catalog of Plant Nematodes (Nematoda. Tylenchida) of Russia's Far East. Vladivostok, Dal'nauka [In Russian].

Volkova, T. V., Klyshevskaya, S. V., Kazachenko, I. P., 2010. The Fauna of Soil-Dwelling Nematodes in Coastal Cenoses of the Lower Amur Basin, The Bulletin of KrasGAU. 7, 81-86 [In Russian].

Wasilewska, L., 1997. Soil Invertebrates as Bioindicators, with Special Reference to Soil-Inhabiting Nematodes, Russian Journal of Nematology. 5, 2, 113-126.

Yeates, G. W., Bongers, T., De Goede, R. G. M., Freckman, D. W., Georgieva, S. S., 1993. Feeding Habits in Soil Nematode Families and Genera - An Outline for Soil Ecologists, Ibid. 25, 315-331. 